\title{
Sperm mitochondria diaphorase activity - a gene mapping study of recombinant inbred strains of mice
}

\author{
ANIELA GOLAS*,1, PAULINA MALEK¹, MALGORZATA PIASECKA ${ }^{2}$ and JOZEFA STYRNA ${ }^{1}$ \\ ${ }^{1}$ Department of Genetics and Evolution, Institute of Zoology, Jagiellonian University, Cracov and \\ ${ }^{2}$ Chair and Department of Histology and Embriology, Pomeranian Medical University, Szczecin, Poland
}

\begin{abstract}
In order to study the genetic control of semen quality parameters, we derived a set of recombinant inbred (RI) mice from crosses between two inbred strains, KE and CBA/Kw, which differ significantly in gamete quality and fertility parameters. In this work, we used male mice from the two parental strains and from ten RI strains to map genes controlling quantitative traits such as sperm mitochondrial diaphorase activity, and assessed the correlation between this trait, sperm motility and in vivo fertilization efficiency. We analyzed sperm mitochondrial dehydrogenase (diaphorase) activity (NADH-dependent NBT assay) cytochemically by means of computerized image densitometry and obtained values for four parameters: 1) integrated optical density (IOD) for all pixels of the midpiece, 2) mean optical density (MOD) for the midpiece pixels, 3) length of sperm midpiece and 4) area of sperm midpiece. Polymorphic microsatellite marker profiles were prepared for $\mathbf{2 0}$ mouse chromosomes in the ten RI strains. We used Map Manager QTX software to correlate the strain distribution patterns (SDPs) of the four measured parameters with the SDPs of the analyzed markers. Hypothetical genes modifying diaphorase activity were mapped to chromosomal region 19q43-19q47, containing, for example, Poll, Sfxn2, Cyp17a1 and Usmg5 genes. Chromosomal regions $18 q 44$ and $18 q 49-18 q 80$ also showed correlation with the SDPs of diaphorase activity. Katnal2, Me2 and Stard6 candidate genes were proposed from this region. Diaphorase activity in the mouse sperm midpiece did not correlate with in vivo fertilization efficiency, but was negatively correlated with the linearity and straightness of sperm movement.
\end{abstract}

KEY WORDS: mouse sperm mitochondria, diaphorase activity, gene mapping

\section{Introduction}

One of the method used to determine the function of a gene, especially when we are interested in a qualitative trait, is knockout technique. Quantitative traits (QTs) controlled by multiple genes require the development of a model population, such as an F2 generation or recombinant inbred (RI) strains. Quantitative trait loci (QTL) controlling, for example, testis weight (Zidek et al. 1998; Bennett et al. 2005), obesity (Cheverud et al. 2004) or alcohol metabolism (Grisel et al. 2002) have been mapped with the use of RI strains of mice. Our department maintains KE and $\mathrm{CBA} / \mathrm{Kw}$ inbred strains of mice, which differ in gamete quality and fertility parameters (Krzanowska 1970; Krzanowska 1976; Kaleta 1977; Styrna 1986; Krzanowska et al. 1995; Styrna and Krzanowska 1995; Golas et al. 2004). A set of RI strains has been developed from these progenitor strains to map genes that control QTs such as sperm motility parameters
(Golas et al. 2004), body mass and sperm head morphology (Golas et al. 2008). In this work we used both parental and RI strains of mice to analyze sperm mitochondrial diaphorase (NADH-dependent dehydrogenase) activity.

Diaphorase controls the ratio between reduced and oxidized forms of NADH; thus it takes part in the sperm energy balance (Atanassov et al. 1987). This oxidoreductase is integrated with the mitochondrial respiratory chain and generates superoxide anions, affecting the level of reactive oxygen species (ROS) (Fraczek and Kurpisz 2005). ROS have been shown to regulate DNA condensation during spermatogenesis, the acrosome reaction, and acquisition of hyperactivated motility by mature

\footnotetext{
Abbreviations used in this paper: IOD, integrated optical density; MOD, mean optical density; QT, quantitative trait; QTL, quantitative trait locus; RI, recombinant inbred strain; SDP, strain distribution pattern.
}

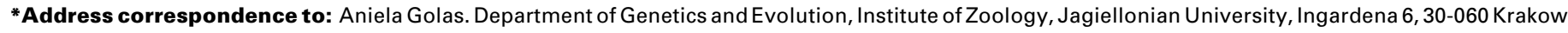
Poland. Fax: +48-012-634-2716. e-mail: aniela.golas@uj.edu.pl
} 


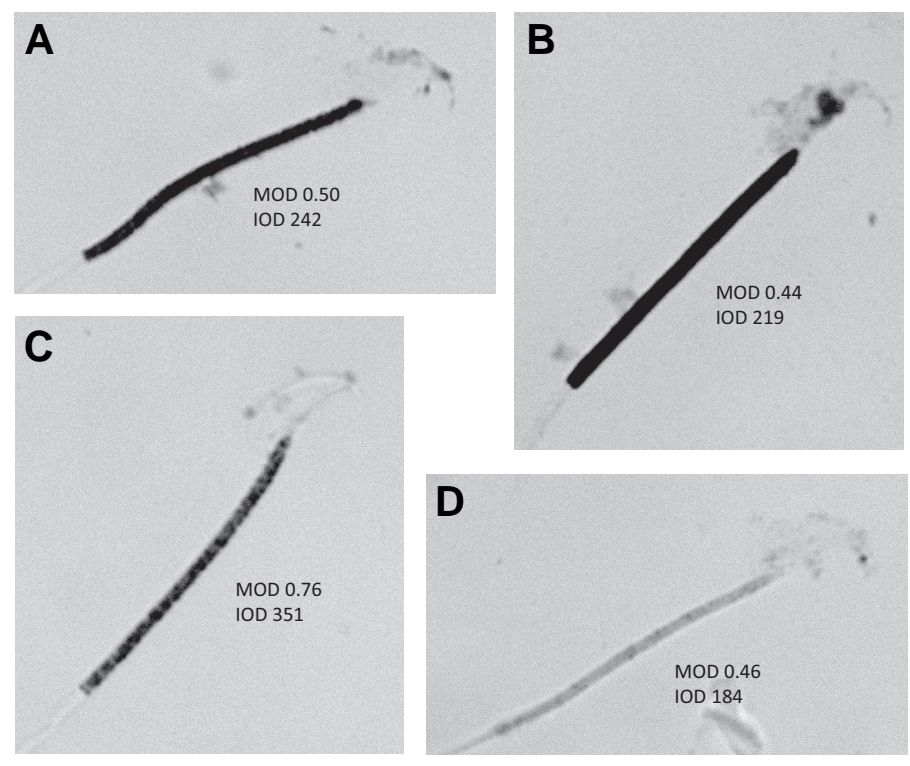

Fig. 1. Cytochemical reaction in mouse sperm midpiece. $1 O D$ (integrated optical density) and MOD (mean optical density) values are presented. Sperms from (A) CBA/Kw males, (B) KE males, (C) RI 17 males (note strong NBT assay) and (D) RI 40 males (note weak NBT assay).

sperms (de Lamirande et al. 1997; Garrido et al. 2004; O’Brien and Zini 2005). Diaphorase activity has been described in the midpiece mitochondrial sheath of boar (Gaczarzewicz et al. 2003), rat (Laszczynska et al. 1999) and human spermatozoa (Piasecka and Kawiak 2003).

We tested diaphorase activity in mouse spermatozoa by a cytochemical reaction. In this NADH-dependent NBT assay, exogenous NADH serves as a donor of hydrogen, which is translocated to the artificial acceptor, NBT (yellow; nitro blue tetrazolium), by the active NADH-dependent dehydrogenase (diaphorase). This leads to the production of reduced tetrazolium salt deposits (dark blue; diformazan) (Fahimi and Karnovsky 1966). The intensity of this reaction depends on diaphorase activity, and can be assessed with a computerized image densitometry analyzer (Quantimet 600 S, Leica, UK) measuring the integrated optical density (IOD) of whole pixels of the midpiece, the mean optical density (MOD) of midpiece pixels (Fig. 1), and the length and the area of the midpiece. These four parameters were evaluated in sperm midpieces of mice from two parental strains, $\mathrm{KE}$ and $\mathrm{CBA} / \mathrm{Kw}$, and from $10 \mathrm{RI}$ strains.

The strain distribution patterns (SDPs) of 195 polymorphic microsatellite sequences were prepared in $10 \mathrm{RI}$ strains. We used Map Manager QTX software (ver. b18; Manly et al. 2001) to correlate microsatellite SDPs with the values of the measured parameters. Two mapped chromosomal regions (one on chromosome 18 and one on chromosome 19) contain genes deemed to modify diaphorase activity, but to support these results further work using the newly developed $\mathrm{RI}$ strains is needed. We also wanted to see whether diaphorase activity in the sperm midpiece correlates with the sperm motility parameters and fertilization efficiency. These results are also presented.

\section{Results}

\section{Microsatellite sequence analysis}

Of the 344 microsatellite sequences analyzed in the mouse genome, 195 revealed PCR product length differences between the two progenitor inbred mouse strains, KE and CBA/Kw. We prepared the SDPs of these polymorphic sequences for $10 \mathrm{RI}$ strains (RI 5, 6, 17, 21, 40, 41, 42, 43, 44 and 49). The average distance between two following markers on the chromosomes was $6.4 \mathrm{cM}$.

\section{Sperm mitochondrial diaphorase activity}

Table 1 gives the results for the cytochemically measured parameters. Average, minimum and maximum values for the four measured parameters are shown in Table 1. The values of the four sperm mitochondria parameters differed significantly between the two progenitor mouse strains, KE and CBA/Kw. Since the IOD and MOD values were not normally distributed, histograms of the IOD distribution in RI 40 and RI 49 sperms are also presented (Fig. 2 A,B).

KE sperms showed a longer mitochondrial sheath but lower midpiece area than $\mathrm{CBA} / \mathrm{Kw}$ sperms. Thus the mitochondrial sheath of KE sperms is thinner that of CBA/Kw sperms. Midpiece length varied little in the analyzed strains: $22.2 \mu \mathrm{m}$ at minimum $(\mathrm{RI}$ 21 males) and $23.5 \mu \mathrm{m}$ at maximum (RI 43 males). Mitochondrial sheath area ranged from $16.0 \mu \mathrm{m}^{2}$ in $\mathrm{RI} 40$ sperms to $22.0 \mu \mathrm{m}^{2}$ in RI 43 sperms.

\section{A}

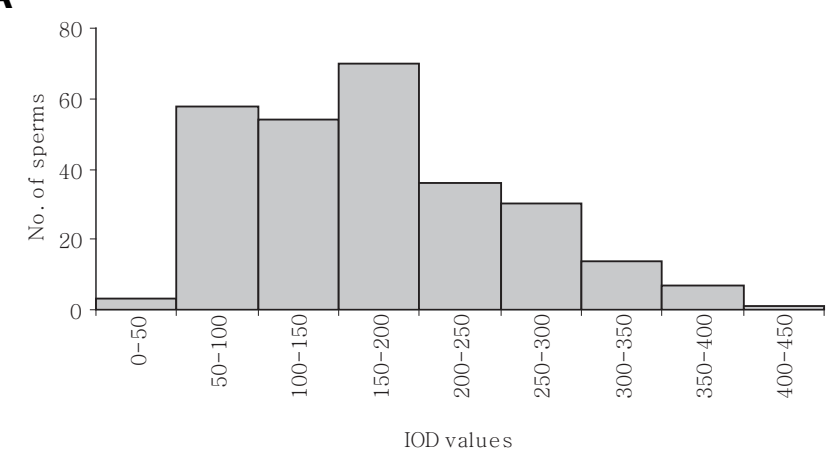

B

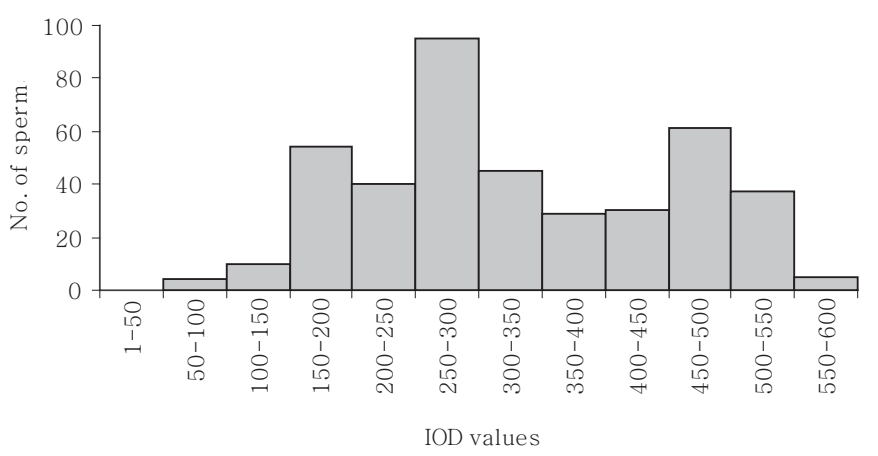

Fig. 2. Non-normal distribution of the integrated optical density (IOD) parameter values. Histogram of IOD value distribution in sperms from (A) RI 40 males and (B) RI 49 males. 
TABLE 1

DIAPHORASE ACTIVITY FOR FOUR SPERM MIDPIECE PARAMETERS: MIDPIECE LENGTH, MIDPIECE AREA, IOD (INTEGRATED OPTICAL DENSITY) AND MOD (MEAN OPTICAL DENSITY)

\begin{tabular}{|c|c|c|c|c|c|}
\hline \multirow[b]{2}{*}{ Inbred strain } & \multicolumn{4}{|c|}{ Cytochemical test results ( $\bar{x} \pm \mathrm{SD})$} & \multirow{2}{*}{$\begin{array}{c}\text { The SDP of } \\
\text { D19Mit53/ D19Mit10 } \\
\text { marker in RI strains }\end{array}$} \\
\hline & $\begin{array}{c}\text { midpiece length } \\
(\mu \mathrm{m})\end{array}$ & $\begin{array}{c}\text { midpiece area } \\
\left(\mu \mathrm{m}^{2}\right)\end{array}$ & $\begin{array}{c}\text { IOD } \\
\text { (integrated optical density) }\end{array}$ & $\begin{array}{c}\text { MOD } \\
\text { (mean optical density) }\end{array}$ & \\
\hline KE & $\begin{array}{l}23.1+/-1.3^{b} \\
(10.7-39.7)^{*}\end{array}$ & $\begin{array}{l}19.3+/-5.5^{b} \\
(15.8-28.4)\end{array}$ & $\begin{array}{c}226.0+/-98.4^{\mathrm{b}} \\
(61-578)\end{array}$ & $\begin{array}{c}0.49+/-0.12^{b} \\
(0.23-0.72)\end{array}$ & - \\
\hline $\mathrm{CBA} / \mathrm{KW}$ & $\begin{array}{c}22.3+/-1.1^{\mathrm{a}} \\
(8.5-34.0)\end{array}$ & $\begin{array}{l}20.1+/-4.2^{\mathrm{a}} \\
(15.0-28.7)\end{array}$ & $\begin{array}{c}257.5+/-84.1^{\mathrm{a}} \\
(59-499)\end{array}$ & $\begin{array}{c}0.55+/-0.10^{a} \\
(0.21-0.83)\end{array}$ & - \\
\hline RI 5 & $\begin{array}{c}22.4+/-1.6^{\text {ab }} \\
(7.7-32.0)\end{array}$ & $\begin{array}{l}18.3+/-4.6^{\mathrm{b}} \\
(6.2-29.7)\end{array}$ & $\begin{array}{c}189.3+1 /-82.1^{a b} \\
(23-373)\end{array}$ & $\begin{array}{c}0.43+/-0.11^{\text {ab }} \\
(0.1-0.64)\end{array}$ & CBA \\
\hline RI 6 & $\begin{array}{c}22.9+/-1.3^{\mathrm{ab}} \\
(8.8-39.7)\end{array}$ & $\begin{array}{l}20.8+/-6.7^{\mathrm{a}} \\
(17.9-33.8)\end{array}$ & $\begin{array}{c}241.7+/-147.7^{b} \\
(40-644)\end{array}$ & $\begin{array}{c}0.46+/-0.15^{\mathrm{ab}} \\
(0.17-0.82)\end{array}$ & $\mathrm{KE} / \mathrm{CBA}$ \\
\hline RI 17 & $\begin{array}{c}22.7+/-1.1^{\text {ab }} \\
(10-34.9)\end{array}$ & $\begin{array}{l}19.8+/-5.0^{\mathrm{a}} \\
(15.8-30.5)\end{array}$ & $\begin{array}{c}396.6+/-186.2^{a b} \\
(95-800)\end{array}$ & $\begin{array}{c}0.82+/-0.22^{\text {ab }} \\
(0.38-1.20)\end{array}$ & KE \\
\hline RI 21 & $\begin{array}{c}22.2+/-1.0^{\mathrm{ab}} \\
(10.1-30.7)\end{array}$ & $\begin{array}{c}19.4+/-4.2^{\mathrm{ab}} \\
(16.0-26.0)\end{array}$ & $\begin{array}{c}287.9+/-117.7^{a b} \\
(44-550)\end{array}$ & $\begin{array}{c}0.63+/-0.20^{a b} \\
(0.16-1.04)\end{array}$ & KE \\
\hline RI 40 & $\begin{array}{c}23.2+/-1.8^{\mathrm{b}} \\
(6.0-23.9)\end{array}$ & $\begin{array}{c}16.0+/-2.5^{\mathrm{ab}} \\
(5.8-29.5)\end{array}$ & $\begin{array}{c}158.2+/-72.9^{\text {ab }} \\
(33-423)\end{array}$ & $\begin{array}{c}0.42+/-0.16^{\text {ab }} \\
(0.14-0.9)\end{array}$ & CBA \\
\hline RI 41 & $\begin{array}{c}23.1+/-1.6^{\mathrm{b}} \\
(2.1-34.5)\end{array}$ & $\begin{array}{l}20.6+1-4.7^{\mathrm{a}} \\
(4.2-28.2)\end{array}$ & $\begin{array}{c}232.3+/-112.8^{\mathrm{b}} \\
(19-668)\end{array}$ & $\begin{array}{c}0.46+/-0.13^{\mathrm{ab}} \\
(0.2-1.03)\end{array}$ & CBA \\
\hline RI 42 & $\begin{array}{c}22.6+/-1.5^{\mathrm{ab}} \\
(2.6-26.6)\end{array}$ & $\begin{array}{c}17.4+/-3.8^{\mathrm{ab}} \\
(3.5-25.7)\end{array}$ & $\begin{array}{c}195.6+/-120.7^{\mathrm{ab}} \\
(19-498)\end{array}$ & $\begin{array}{c}0.46+/-0.20^{\mathrm{ab}} \\
(0.17-0.97)\end{array}$ & CBA \\
\hline RI 43 & $\begin{array}{c}23.5+/-1.3^{\mathrm{ab}} \\
(2.7-31.0)\end{array}$ & $\begin{array}{c}22.0+/-4.5^{\mathrm{ab}} \\
(2.5-28.4)\end{array}$ & $\begin{array}{c}302.1+/-132.9^{a b} \\
(26-672)\end{array}$ & $\begin{array}{l}0.57+/-0.15^{\mathrm{a}} \\
(0.2-0.99)\end{array}$ & KE \\
\hline RI 44 & $\begin{array}{c}23.0+/-1.2^{\mathrm{ab}} \\
(11.0-28.8)\end{array}$ & $\begin{array}{l}18.5+/-3.6^{\mathrm{b}} \\
(17.0-27.6)\end{array}$ & $\begin{array}{c}203.9+/-100.5^{\mathrm{ab}} \\
(59-530)\end{array}$ & $\begin{array}{c}0.46+/-0.14 \text { ab } \\
(0.15-0.94)\end{array}$ & CBA \\
\hline RI 49 & $\begin{array}{c}23.1+/-1.4^{\mathrm{ab}} \\
(4.9-39.7)\end{array}$ & $\begin{array}{c}19.2+/-3.4^{\mathrm{ab}} \\
(6.4-30.7)\end{array}$ & $\begin{array}{c}311.5+/-116.4^{\mathrm{ab}} \\
(64-575)\end{array}$ & $\begin{array}{c}0.69+/-0.17^{\text {ab }} \\
(0.29-1.09)\end{array}$ & KE \\
\hline
\end{tabular}

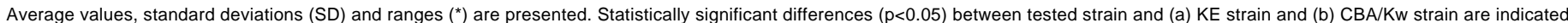

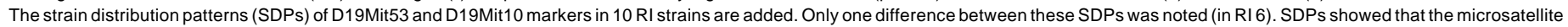
marker derived from the KE strain correlates with increased IOD values.

TABLE 2

\section{MARKER REGRESSION PROCEDURE: CORRELATIONS BETWEEN VALUES OF THE MEASURED PARAMETERS AND MICROSATELLITE SDPS}

\begin{tabular}{|c|c|c|c|c|c|c|c|c|c|c|}
\hline \multicolumn{6}{|c|}{ Marker regression analysis } & \multirow[b]{2}{*}{ Additive effect } & \multirow{2}{*}{$\begin{array}{l}\text { Peak } \\
\text { LRS } \\
\text { value }\end{array}$} & \multicolumn{3}{|c|}{$\begin{array}{l}\text { Significance thresholds } \\
\text { for peak LRS value }\end{array}$} \\
\hline Parameter & Marker & Locus & LRS & $\%$ & $\mathbf{p}$ & & & $p=0.63$ & $\mathrm{p}=0.05$ & $\mathrm{p}=0.001$ \\
\hline \multirow{2}{*}{ Midpiece area } & D7Mit267 & $7 q 11$ & 10.9 & 66 & 0.00098 & 1.59 & 12.5 & 10.1 & 15.6 & 21.7 \\
\hline & D8Mit104 & $8 q 37$ & 13.7 & 70 & 0.00049 & 1.6 & 13.7 & 9.9 & 15.6 & 21.0 \\
\hline \multirow{7}{*}{ IOD } & D18Mit33 & $18 q 44$ & 14.8 & 77 & 0.00012 & 60.15 & \multirow{3}{*}{15.1} & \multirow{3}{*}{10.7} & \multirow{3}{*}{17.0} & \multirow{3}{*}{24.0} \\
\hline & D18Mit49 & $18 q 49$ & 14.8 & 77 & 0.00012 & 60.15 & & & & \\
\hline & D18Mit80 & $18 q 50$ & 14.8 & 77 & 0.00012 & 67.93 & & & & \\
\hline & D19Mit106 & $19 q 22$ & 14.8 & 77 & 0.00012 & 67.93 & \multirow{4}{*}{16.6} & \multirow{4}{*}{10.6} & \multirow{4}{*}{17.0} & \multirow{4}{*}{23.0} \\
\hline & D19Mit13 & $19 q 33$ & 13.8 & 75 & 0.0002 & 56.25 & & & & \\
\hline & D19Mit53 & $19 q 43$ & 13.8 & 75 & 0.0002 & 56.25 & & & & \\
\hline & D19Mit10 & $19 q 47$ & 14.8 & 77 & 0.00012 & 60.15 & & & & \\
\hline \multirow{5}{*}{ MOD } & D18Mit33 & $18 q 44$ & 15.6 & 79 & 0.00008 & 0.1 & \multirow{3}{*}{15.7} & \multirow{3}{*}{10.3} & \multirow{3}{*}{20.4} & \multirow{3}{*}{35.8} \\
\hline & D18Mit49 & $18 q 49$ & 15.6 & 79 & 0.00008 & 0.1 & & & & \\
\hline & D18Mit80 & $18 q 50$ & 14.5 & 77 & 0.00014 & 0.11 & & & & \\
\hline & D19Mit106 & $19 q 22$ & 14.5 & 77 & 0.00014 & 0.11 & \multirow{2}{*}{15.6} & \multirow{2}{*}{10.5} & \multirow{2}{*}{20.2} & \multirow{2}{*}{36.8} \\
\hline & D19Mit10 & $19 q 47$ & 15.6 & 79 & 0.00008 & 0.1 & & & & \\
\hline
\end{tabular}

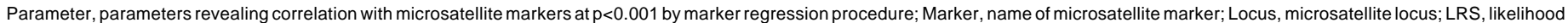

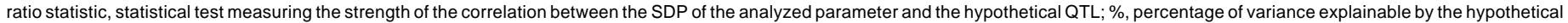

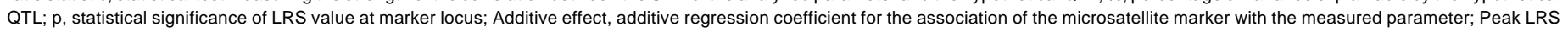

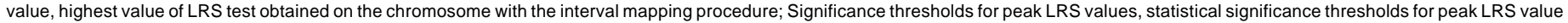
estimated with permutation test (for 5000 and with $1 \mathrm{cM}$ interval) in the whole genome scan.

Both IOD (integrated optical density) and MOD (mean optical density) were higher in $\mathrm{CBA} / \mathrm{Kw}$ than in $\mathrm{KE}$ males. For all tested inbred strains the correlation coefficient for IOD and MOD parameters was $r=0.9(p<0.05)$. Gametes from RI strains 17,21 and 49 had higher IOD and MOD values than those of the two parental strains $(p<0.05)$; sperms from RI strains 5, 40, 42 and 44 had lower IOD and MOD values than those of the two parental strains $(p<0.05)($ Table 1).

\section{Mapping procedure}

Correlations at $p<0.001$ obtained from the marker regression procedure are presented in Table 2 . The interval mapping at $1 \mathrm{cM}$ 
A

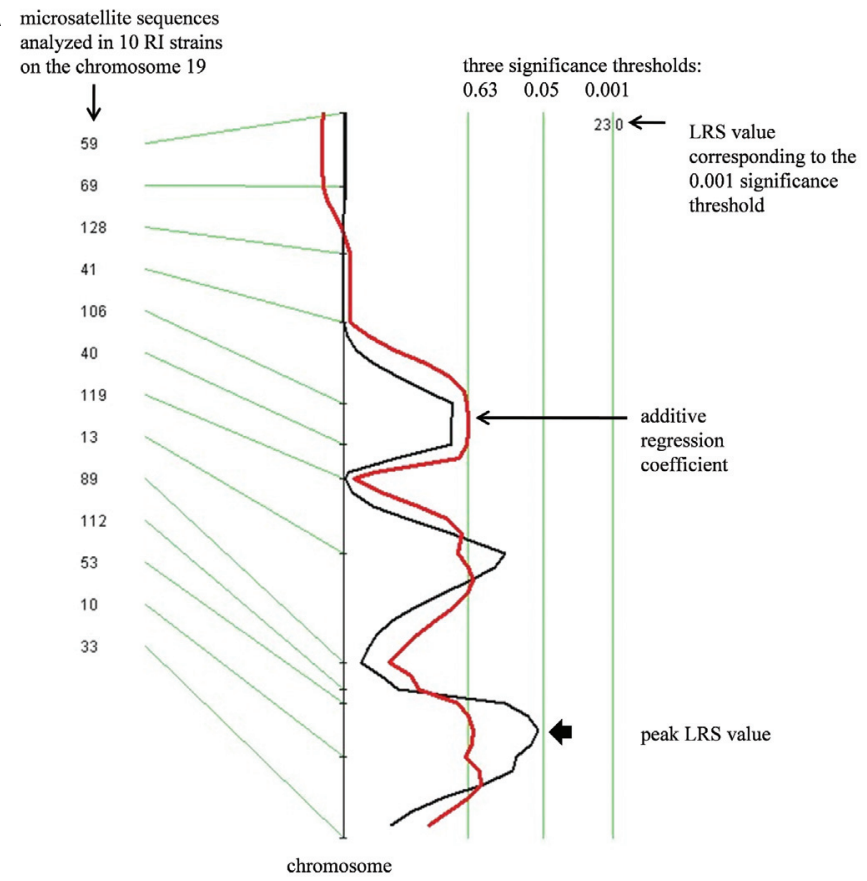

B

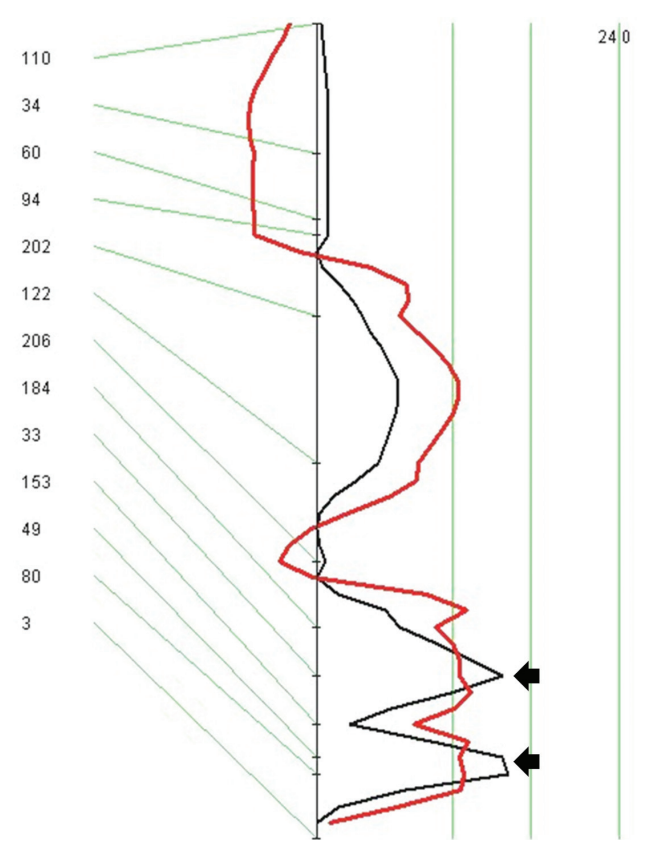

Fig. 3. The interval mapping procedure results of the gene(s) controlling the integrated optical density (IOD) parameter. Suggestive correlations between IOD parameter and hypothetical QTL located on chromosomes (A) 19 and (B) 18 are shown (arrowheads).

intervals showed suggestive correlation of sperm mitochondria diaphorase activity with one chromosomal region spanning $19 q 43$ to $19 q 47$ (45-47 Mbp; Fig. 3A) and two chromosomal regions on chromosome 18 (18q44, 69 Mbp and 18q49-18q50, 69-77 Mbp; Fig. 3B). Although the strength of these associations was suggestive only, the mapped chromosomal region was searched for candidate genes possibly regulating diaphorase activity.

In chromosomal region 19q43-19q47 a gene coding for polymerase lambda ( $P o /)$ is proposed, as $P$ ol/knockout male mice are infertile (Kobayashi et al. 2002). Cyp17a1, coding for the cytochrome P450 subunit, could also be functionally related to diaphorase activity. Two other genes, Sfxn2and Usmg5, coding for mitochondrial inner membrane proteins, could be related to diaphorase activity.

Chromosomal region 18q44 contains two genes possibly controlling diaphorase activity: Stard6 (StAR-related lipid transfer (START) domain containing 6) expressed exclusively in male germ cells (Bose et al. 2008), and Me2(malic enzyme 2, $N A D(+)$ dependent, mitochondria) coding for mitochondrial enzyme. Katnal2 (katanin p60 subunit $A$-like 2) is the only candidate gene

\section{TABLE 3}

\section{CORRELATIONS $\left(r_{s}\right)$ BETWEEN SEVEN SPERM MOTILITY PARAMETERS AND FOUR CYTOCHEMICALLY MEASURED PARAMETERS}

\begin{tabular}{cccccccc} 
Parameter & InVAP & InVSL & InVCL & InALH & InBCF & arcsinLIN & arcsinSTR \\
\hline midpiece area & -0.34 & -0.39 & -0.34 & -0.34 & 0.44 & -0.18 & 0.06 \\
midpiece length & 0.28 & 0.34 & 0.28 & 0.23 & 0.23 & 0.05 & -0.14 \\
IOD & 0.00 & -0.18 & 0.00 & 0.08 & 0.15 & $-\mathbf{0 . 7 1 *}$ & -054 \\
MOD & 0.00 & -0.19 & 0.00 & 0.12 & -0.09 & $-\mathbf{0 , 7 8 *}$ & $-\mathbf{0 . 6 6 *}$ \\
\hline
\end{tabular}

* - correlation statistically significant at $p<0.05$. located in the 18q49-18q50 chromosomal region; it codes for a microtubule component protein showing ATPase activity.

\section{Correlations between the diaphorase activity, sperm motility parameters and fertilization efficiency}

The results for correlations between diaphorase activity and motility parameters are presented in Table 3. Mean optical density (MOD) correlated negatively with sperm movement linearity (LIN) and straightness (STR). Diaphorase activity did not correlate with in vivo fertilization efficiency, regardless of the cross type (Table 4). Of the seven motility parameters, four correlated positively with fertilization efficiency (VCL, VSL, VAP and ALH) only in crosses between females and males of the same strain (Table 4).

\section{Discussion}

The molecular background of sperm quality parameters has been studied in several animal models. One molecule used in such studies is sperm mitochondrial diaphorase. This protein is one of about $99 \%$ of mitochondrial proteins that are encoded by genomic DNA (Szibor and Holtz 2003). No relationship was found between diaphorase activity and diaphorase electrophoretic patterns (Gavella and Lipovac 1992); in this work we used recombinant inbred (RI) strains of mice to map genes controlling diaphorase (NADH-dependent dehydrogenase) activity. Diaphorase is active in the sperm mitochondrial sheath and can be evaluated cytochemically. Our previous works on the RI strains enabled us to correlate diaphorase activity with sperm motility characteristics and in vivo fertilization efficiency.

IOD was significantly higher in CBA/Kw that KE sperm, but was elevated in RI strains possessing D19Mit53 and D19Mit10 microsatellite markers derived from the KE strain (Table 1). High 
additive coefficient values also suggested that the $\mathrm{KE}$ allele increased IOD (Table 2). The current genetic constitution of the RI strains apparently is a consequence of the crossing-over between microsatellite markers and gene(s) controlling the IOD parameter. After the recombination process at the very beginning of the breeding history of the RI strains, this new genetic composition was inherited by further generations and persist in the RI strains tested in our laboratory.

Male gamete mitochondria become ubiquitinated during spermatogenesis and are effectively eliminated in fertilized oocytes (Sutovsky et al. 2004). In our animal model, mice from RI strains inherited maternal mitochondria from CBA/Kw (RI 17 and $R I 21)$ or KE females (the rest of the RI strains), depending on the type of cross between parental strains. The data we obtained here showed that sperm mitochondrial diaphorase activity is not strongly correlated with mitochondrial (and mtDNA) origin (Table 1). Thus, major genes controlling it seem to be located in the genomic DNA. We designed this study to map these genes and found that the distribution of the IOD and MOD values correlated with three chromosomal regions. Region 19q43-19q47 spans between $45 \mathrm{Mbp}$ and $47 \mathrm{Mbp}$ of 19 chromosome (i.e., between microsatellite markers D19Mit53 and D19Mit10), the other is located within $69 \mathrm{Mbp}(18 \mathrm{q} 44$, close to D18Mit33) and third one spans between 76-77Mbp (18q49-18q50, between D18Mit49 and D18Mit80) of chromosome 18.

Chromosomal region 19q43-19q47 contains several genes that could influence the activity of sperm mitochondria NADHdependent dehydrogenase (diaphorase). Among them is Poll, Cyp17a1, Stxn2and Usmg5. Three other genes on the chromosome 18 are proposed. Our results showed a correlation between diaphorase activity and sperm movement linearity and straightness. Thus, Katnal2 (18q49-18q80) was listed due to its microtubulesevering ATPase activity. From chromosomal region 18q44, Me2 and Stard6 might also influence diaphorase activity.

Presented mapping results are based on segregating pattern similarities between chromosomal regions and sperm diaphorase activity values, but they are only suggestive. In our breeding department we have developed F13-F16 generations of eight

\section{TABLE 4}

\section{CORRELATIONS ( $r$ ) BETWEEN ANALYZED SEMEN PARAMETERS AND IN VIVO FERTILIZATION EFFICIENCY IN RI STRAINS}

\begin{tabular}{ccc} 
& $\begin{array}{c}\text { Sperm motility parameters and parameters measured cytochemically } \\
\text { were correlated with in vivo fertilization efficiency using: }\end{array}$ \\
\cline { 2 - 3 } Parameter & $\begin{array}{c}\text { females and males from the same } \\
\text { RI strain }\end{array}$ & $\begin{array}{c}\text { outbred females and males from } \\
\text { RI strains }\end{array}$ \\
\hline InVAP & $\mathbf{0 . 6 3}^{*}$ & 0.27 \\
InVSL & $\mathbf{0 . 6 0}^{*}$ & 0.21 \\
InVCL & $\mathbf{0 . 6 6}^{*}$ & 0.28 \\
InALH & $\mathbf{0 . 7 1}^{*}$ & 0.34 \\
InBCF & -0.18 & -0.55 \\
arcsinLIN & -0.20 & -0.26 \\
arcsinSTR & -0.25 & -0.31 \\
midpiece area & 0.29 & 0.04 \\
midpiece length & 0.10 & 0.01 \\
IOD & 0.41 & 0.29 \\
MOD & 0.39 & 0.36 \\
\hline
\end{tabular}

* - correlation statistically significant at $p<0.05$. new RI strains. We will analyze the microsatellite markers and sperm quality parameters in these additional strains, to improve the statistical significance of the correlations. To prepare denser marker profile in the RI strains we will also analyze other polymorphisms (e.g., SNP and RFLP).

The cytochemical test we used here allowed us to analyze the length and the area of the spermatozoan midpieces. In human, the area of the midpiece is important for sperm motility (Piasecka et al. 2003, 2004). In mice we found no correlation between motility parameters and midpiece area or length (Table 3). Sperm midpiece length shows little variation in males of the same species (Beatty 1971, Olds-Clarke 2003), and our data support this observation (Table 1).

The relationship between diaphorase activity and sperm motility seems to be species-dependent. A weak cytochemical reaction was frequently noted in sperms from patients with low sperm motility (Piasecka and Kawiak 2003). In boar, the mean diaphorase activity (MOD) parameter was shown to be significantly correlated with the percentage of spermatozoa with progressive motility (Gaczarzewicz et al. 2003). Our detailed analysis of sperm motility and of correlation between motility parameters and diaphorase activity revealed a significant negative correlation between mean diaphorase activity (MOD) and the linearity (LIN) and straightness (STR) of sperm motility. There was no connection between the MOD parameter and the velocity parameters (VCL, VSL and VAP) or beat cross frequency (BCF; Table 3).

Previously we showed that BCF is under the control of genes located in chromosomal region 7q11 (Golas et al. 2004). Gapdhs (glyceraldehyde-3-phosphate dehydrogenase, spermatogenic) is also located in this region of chromosome 7 . Its function in sperm motility control was observed in knockout male mice (Miki et al. 2004). Sperms of Gapdhs mutants were motile but did not reveal progressive movement, and other CASA parameters were also decreased. Sperm metabolism is partially species-dependent, but the analysis of Gapdhs mutants showed that glycolysis, not oxidative phosphorylation, is the main source of the energy needed for sperm forward motility. Those findings suggest that different sperm motility parameters rely on different energy sources. Moreover, spermatozoan movement characteristics can be regulated by independent processes and genes. This could be a reason why only the linearity and straightness of sperm movement correlated with mitochondrial diaphorase activity in our study.

Human semen quality correlates with respiratory chain functioning in sperm mitochondria (Ruiz-Pesini et al. 2000). The in vivo fertilization efficiency of our mice was not correlated with diaphorase activity, regardless of which females were used; thus the function of this enzyme in sperm mitochondria is speciesspecific. Fertilization outcome correlated positively with the sperm velocity parameters (VCL, VSL and VAP) and the amplitude of lateral head displacement $(A L H)$ in $R I \times R I$ crosses, but not in crosses between outbred females and RI males (Table 4). These differences suggested that oocytes origin (and quality) rather than sperm motility parameters are responsible for the observed correlations. It is not the first time such compensation of gamete quality was observed in our department (Wabik-Sliz et al. 2005).

To summarize, we showed that sperm mitochondrial diaphorase activity is under the control of genes located in chromosomal region $19 q 43-19 q 47,18 q 44$ and $18 q 49-18 q 80$. These data need 
further investigation with the use of newly developed RI strains and denser markers such as SNP or RFLP. Diaphorase activity in mouse sperm mitochondria was negatively correlated with the linearity and straightness of sperm movement, but neither diaphorase activity nor LIN and STR influenced in vivo fertilization efficiency. Velocity parameters and lateral sperm head amplitude correlated positively with in vivo fertilization efficiency.

\section{Materials and Methods}

\section{Mice}

We used groups of 5-8 adult male mice (3-8 months) from two progenitor inbred mouse strains, $\mathrm{KE}$ and $\mathrm{CBA} / \mathrm{Kw}$, and from $10 \mathrm{RI}$ strains maintained in our Department. Two RI strains were developed from crosses between CBA/Kw females and KE males (CBXE strain 17 and 21 ), and eight $R I$ strains were derived from reciprocal crosses between $\mathrm{KE}$ females and CBA/Kw males (EXCB strain 5, 6, 40, 41, 42, 43, 44 and 49). All animals were given a standard pelleted diet (Labofeed $B$, Kcynia) and water ad libitum, and were kept under 12L:12D conditions.

\section{Microsatellite sequence analysis}

Genomic DNA was isolated from mouse tails using a standard phenolchloroform protocol, and 344 microsatellite sequences in KE and CBA/Kw strains were scanned by PCR and electrophoresis. Primer sequences were derived from the Jackson Laboratory database (www.jax.org). PCR was carried out for 30-35 cycles, in total volume of $15 \mu \mathrm{l}$, under the following conditions (Biometra, T-gradient): $30 \mathrm{~s}$ at $94^{\circ} \mathrm{C}, 30 \mathrm{~s}$ of primer annealing at temperature depending on the primer pair used, and extension at $72^{\circ} \mathrm{C}$ with Taq polymerase for $30 \mathrm{~s}$. PCR products were electrophoresed on $3.5 \%$ agarose gel stained with ethidium bromide.

To prepare marker maps for 20 chromosomes of the mouse genome, 195 sequences that were polymorphic in KE and CBA/Kw strains were further analyzed in $10 \mathrm{RI}$ strains. The obtained polymorphisms between $\mathrm{KE}$ and $\mathrm{CBA} / \mathrm{Kw}$ strains and the SDPs of these polymorphic microsatellites in RI strains were placed in the Mouse Genetics Database (www.informatics.jax.org; accession IDs: J:84237, J:90435, J:104037 and J:121994).

\section{Cytochemistry}

NADH-dependent NBT assay were done to access the activity of mouse sperm mitochondrial NADH-dependent dehydrogenases. Male mice were killed by cervical dislocation, both vas deferens were dissected, and their content was gently squeezed out into $100 \mu$ PBS in 1.5 $\mathrm{ml}$ tubes. Sperms were allowed to disperse for $5 \mathrm{~min}$ and $400 \mu \mathrm{l}$ PBS was added. Centrifugation at $1000 \mathrm{rpm}$ for $4 \mathrm{~min}$ and washing the sperm pellet with $500 \mu$ I PBS was done twice. The collected spermatozoa were resuspended in $100 \mu$ I PBS.

For each $100 \mu \mathrm{l}$ of spermatozoa suspension, $400 \mu \mathrm{l}$ incubation medium was prepared using the following substrates: $\mathrm{NADH}(2.64 \mathrm{mmol} /$ L), NBT (1.5 mmol/L), BSA (essentially fatty acid free, fraction $\mathrm{V} ; 0.125 \%$ $\mathrm{w} / \mathrm{v}), \mathrm{MgCl}_{2}(6.25 \mathrm{mmol} / \mathrm{L})$ and $1 \%$ Triton X-100 (0.025\% v/v) diluted in PBS. Sperms were gently mixed with the medium and incubated in the dark for 60 min at $37^{\circ} \mathrm{C}$. Two smears of each spermatozoa suspension were prepared and air-dried, then washed in PBS and fixed for $10 \mathrm{~min}$ in $2 \%$ glutaraldehyde $(25 \%$, Grade II, Sigma-Aldrich) in $0.1 \mathrm{M}$ cacodylate buffer. After washing in distilled water and air-drying, cover slides were mounted using transparent Entellan (Merck, Germany).

In the cytochemical reaction, active mouse sperm mitochondrial $\mathrm{NADH}$-dependent dehydrogenase (diaphorase) translocates hydrogene from exogenous NADH to the artificial hydrogene acceptor NBT (nitro blue tetrazolium). Reduced NBT salt forms dark blue deposits (diformazans) in the sperm midpiece. The intensity of this reaction depends on diaphorase activity and can be assessed by an optical density computerized image analyzer (Quantimet 600 S, Leica, UK), with grades of grayness (range 0-255) replaced by optical density values (range 0-2) (Fig. 1). Each male mouse was represented by an analysis of 100 sperm midpieces under LM (40x objective). Four parameters were measured for a single midpiece: a) IOD (integrated optical density), the sum of the optical densities of pixels in the midpiece, b) MOD (mean opticaldensity), the average optical density of the midpiece pixels, c) midpiece area, and d) midpiece length.

\section{Correlations between diaphorase activity, sperm motility param- eters and in vivo fertilization efficiency}

The sperm motility of males from $\mathrm{KE}, \mathrm{CBA} / \mathrm{Kw}$ and $\mathrm{RI}$ strains was analyzed using computer-assisted semen analysis system (CASA, ver. 10, Hamilton Thorne Research, Beverly, Mass.). Seven parameters were calculated for each semen sample after $1.5 \mathrm{~h}$ incubation at $37^{\circ} \mathrm{C}$ and $5 \%$ $\mathrm{CO}_{2}$ : curvilinear, straight line and average path velocity (VCL, VSL and VAP), lateral head displacement amplitude (ALH), beat cross frequency (BCF) and sperm movement linearity (LIN, VSL/VCL) and straightness (STR, VSL/VAP). The experimental conditions and data obtained are described in detail elsewhere (Golas et al. 2004).

In vivo fertilization efficiency was analyzed previously in our department, using matings between females and males from the same RI strain (pure mating) as well as between our outbred females and RI males (males testing). Briefly, one day after the copulation plug was found, the females were killed, the ova were flushed from oviducts, and two-cell embryos were counted. The experimental procedures and results were described by Wabik-Sliz et al. (2005).

\section{Statistical analysis}

For statistical purposes the data for four measured sperm mitochondria parameters were pooled by mouse strain. Nonparametric ANOVA was applied (Kruskal-Wallis test; Statistica 6.0) to test the significance of differences between strains. Differences were taken to be statistically significant at $p<0.05$

The marker regression procedure was performed with Map Manager QTX ver. b18 software (Manly et al. 2001) to search for microsatellite markers that correlate (LRS test, likelihood ratio statistic) with the SDPs of four analyzed parameter values at $p<0.001$ using Kosambi function (i.e., with the middle interference rate). The interval mapping procedure was used to evaluate LRS values at $1 \mathrm{cM}$ intervals to determine the most possible loci of the hypothetical genes deemed to control measured traits. The additive coefficients were also evaluated. Three statistical significance thresholds were estimated with a permutation test (for 5000 iterations) for the whole-genome empirical probability of the relationship between the hypothetical locus of the gene and the value of the trait: $p<0.63$ for a suggestive correlation, $p<0.05$ for a statistically significant correlation, and $p<0.001$ for a highly significant correlation (Chmielewicz and Manly, 2002; Li et al. 2005).

The chromosomal locations of the markers correlating with the SDPs of the measured parameters were confirmed by their base pair positions in the www.ensembl.org database. Chromosomal regions revealing LRS test values above the $p<0.05$ statistical significance threshold were searched in the mouse genome database (www.ncbi.nih.gov) for candidate genes.

Motility parameter values were not normally distributed; before statistical analysis they were normalized by natural logarithms (VCL, VSL, VAP, ALH, BCF). Percentage values (LIN, STR) were transformed using arcsin function. Spearman's correlation coefficients $\left(r_{S}\right)$ were calculated between the average values of normalized motility parameters and the average values of the four parameters. We applied Pearson's correlation coefficient $(r)$ to correlate in vivo fertilization efficiency with motility parameters and the four parameters analyzed here. In both cases $p<0.05$ was taken as the level of statistical significance.

\section{Acknowledgements}

This work was founded by the Institute of Zoology of the Jagiellonian 
University (DS/BINoZ/IZ/775/2007, DS/775-K/ZDS/000786).

\section{References}

ATANASSOV B, DENKOVA R, GEORGIEV G (1987). Activity and localization of NADH-dependant oxidoreductase (diaphorase) in boar spermatozoa. Andrologia 19: 474-477.

BEATTY, R.A. (1971). The genetics of size and shape of spermatozoan organelles. In The Genetics of the Spermatozoon (Eds. R.A. Beatty and S. GluecksohnWaelsch). University of Edinburgh, pp 97-115.

BENNETT B, CAROSONE-LINK PJ, LU L, CHESLER EJ, JOHNSON TE (2005). Genetics of body weight in the LXS recombinant inbred mouse strains. Mamm Genome 16: 764-774.

BOSE HS, WHITTAL RM, RAN Y, BOSE M, BAKER BY, MILLER WL (2008). StARlike activity and molten globule behavior of StARD6, a male germ-line protein. Biochemistry 47: 2277-2288.

CHEVERUD JM, EHRICH TH, HRBEK T, KENNEY JP, PLETSCHER LS, SEMENKOVICH CF (2004). Quantitative trait loci for obesity- and diabetesrelated traits and their dietary responses to high-fat feeding in LGXSM recombinant inbred mouse strains. Diabetes 53: 3328-3336.

CHMIELEWICZ, K.M., MANLY, K.F. (2002). User manual for QTX. Software for genetic mapping of Mendelian markers and quantitative trait loci. Revised for QTX b17, Roswell Park Center Institute.

DE LAMIRANDE E, JIANG H, ZINI A, KODAMA H, GAGNON C (1997). Reactive oxygen species and sperm physiology. Rev Reprod 2: 48-54.

FAHIMI HD, KARNOVSKY MJ (1966). Cytochemical localization of two glycolytic dehydrogenases in white skeletal muscle. J Cell Bio/29: 113-128.

FRACZEK M, KURPISZ M (2005). The redox system in human semen and peroxidative damage of spermatozoa. Postepy Hig Med Dosw (online) 59: 523534.

GARRIDO N, MESEGUER M, ALVAREZ J, SIMON C, PELLICER A, REMOHI J (2004). Relationship among standard semen parameters, glutathione peroxidase/glutathione reductase activity, and mRNA expression and reduced glutathione content in ejaculated spermatozoa from fertile and infertile men. Fertil Steril 82, Suppl 3: 1059-1066.

GAVELLA M, LIPOVAC V (1992). NADH-dependent oxidoreductase (diaphorase) activity and isozyme pattern of sperm in infertile men. Arch Andro/28: 135-141.

GACZARZEWICZ D, PIASECKA M, UDALA J, BLASZCZYK B, LASZCZYNSKA M, KRAM A (2003). Oxiduoreductive capability of boar sperm mitochondria in fresh semen and during their preservation in BTS extender. Reproductive Biology 3 : 161- 172.

GOLAS A, GRZMIL P, MULLER CH, STYRNA J (2004). Chromosome 7q11 controls sperm beat cross frequency (BCF) in mice. Folia biol (Krakow)52: 211217.

GOLAS A, DZIEZA A, KUZNIARZ K, STYRNA J (2008) Gene mapping of sperm quality parameters in recombinant inbred strains of mice. Int J Dev Bio/52: 287293.

GRISEL JE, METTEN P, WENGER CD, MERRILL CM, CRABBE JC (2002). Mapping of quantitative trait loci underlying ethanol metabolism in BXD recombinant inbred mouse strains. Alcohol Clin Exp Res 26: 610-616.

KALETA E (1977). Influence of genetic factors on the fertilization of mouse ova in vitro. J Reprod Fert 51: 375-381.

KOBAYASHI Y, WATANABE M, OKADA Y, SAWA H, HIROYUKI T, NAKANISHI M, KAWASE Y, SUZUKI H, NAGASHIMA K, IKEDA K, MOTOYAMA N (2002). Hydrocephalus, situs inversus, chronic Sinusitis, and male infertility in DNA a - polymerase deficient mice: possible implication for the pathogenesis of immotile cilia syndrome. Mol Cel/ Bio/22: 2769-2776.

KRZANOWSKA H (1970). Relation between fertilization rate and penetration of eggs by supplementary spermatozoa in different mouse strains and crosses. $J$ Reprod Fert 22: 199-204.

KRZANOWSKA H (1976). Types of sperm-head abnormalities in four inbred strains of mice. Acta Biologica Cracoviensia, Series: Zoologia 19: 79-85.

KRZANOWSKA H, STYRNA J, WABIK-SLIZ B (1995). Analysis of sperm quality in recombinant inbred mouse strains: correlation of sperm head shape with sperm abnormalities and with the incidence of supplementary spermatozoa in the perivitelline space. J Reprod Fertil 104: 147-154.

LASZCZYNSKA M, PIASECKA M, KRAM A (1999). Alterations in the mitochondria of rat spermatozoa after experimantal hyperprolactinemia. Folia Histochem Cytobio/37: 87-88.

LI R, LYONS MA, WITTENBURG H, PAIGEN B, CHURCHIL GA (2005). Combining data from multiple inbred line crosses improves the power and resolution of QTL mapping. Genetics 169: 1699-1709.

MANLY KF, CUDMORE RH JR, MEER JM (2001). Map Manager QTX, cross platform software for genetic mapping. Mamm Genome 12: 930-932.

MIKI K, WILLIS WD, BROWN PR, GOULDING EH, FULCHER KD, EDDY EM (2002). Targeted disruption of the Akap4 gene causes defects in sperm flagellum and motility. Dev Bio/248: 331-342.

O'BRIEN J, ZINI A (2005). Sperm DNA integrity and male infertility. Urology65: 1622.

OLDS-CLARKE P (2003). Unresolved issues in mammalian fertilization. Int Rev Cyto/232: 129-184.

PIASECKA M, LASZCZYNSKA M, GACZARZEWICZ D (2003). Morphological and functional evaluation of spermatozoa from patients with asthenoteratozoospermia. Folia Morpho/62: 479-481.

PIASECKA M, GACZARZEWICZ D, KURZAWA R, LASZCZYNSKA A, KRAM A (2004). Diagnostic evaluation of oxidoreductive capability of sperm mitochondria. Roczniki Akademii Medycznej w Bialymstoku 49, Suppl 1, Proceedings: 108-110.

PIASECKA M, WENDA-ROZEWICKA L, OGONSKI T (2001). Computerized analysis of cytochemical reactions for dehydrogenases and oxygraphic studies as methods to evaluate the function of the mitochondrial sheath in rat spermatozoa. Andrologia 33: 1-12.

RUIZ-PESINI E, LAPENA AC, DIEZ C, ALVAREZ E, ENRIQUEZ JA, LOPEZPEREZ MJ (2000). Seminal quality corelates with mitochondrial functionality. Clin Chim Acta 300: 97-105.

STYRNA J (1986). Solubility of zonae pellucidae of unfertilized and fertilized mouse ova in different chemical reagents. Zwierzeta Laboratoryjne 23: 3-10.

STYRNA J, KRZANOWSKA H (1995). Sperm select penetration test reveals differences in sperm quality in strains with different $Y$ chromosome genotype in mice. Arch Andro/53: 111-118.

SUTOVSKY P, VAN LEYEN K, MCCAULEY T, DAY BN, SUTOVSKY M (2004). Degradation of paternal mitochondria after fertilization: implications for heteroplasmy, assisted reproductive technologies and mtDNA inheritance. Reprod Biomed (online) 8: 24-33.

WABIK-SLIZ B, GOLAS A, KRZANOWSKA H (2005). Analysis of oocyte quality in recombinant inbred mouse strains developed from KE and CBA strains that differ in fertilization efficiency. J App/ Genet 46: 163-170.

ZIDEK V, MUSILOVA A, PINTIR J, SIMAKOVA M, PRAVENEC M (1998). Genetic dissection of testicular weight in the mouse with the BXD recombinant inbred strains. Mamm Genome 9: 503-505. 


\section{Further Related Reading, published previously in the Int. J. Dev. Biol.}

See Special Issue Pattern Formation edited by Michael K. Richardson and Cheng-Ming Chuong at:

http://www.ijdb.ehu.es/web/contents.php?vol=53\&issue=5-6

Mammalian sperm metabolism: oxygen and sugar, friend and foe Bayard T. Storey

Int. J. Dev. Biol. (2008) 52: 427-437

Gene mapping of sperm quality parameters in recombinant inbred strains of mice Aniela Golas, Anna Dzieza, Katarzyna Kuzniarz and Jozefa Styrna

Int. J. Dev. Biol. (2008) 52: 287-293

Sperm-activating peptides in the regulation of ion fluxes, signal transduction and motility

Alberto Darszon, Adán Guerrero, Blanca E. Galindo, Takuya Nishigaki and Christopher D. Wood

Int. J. Dev. Biol. (2008) 52: 595-606

A systematic molecular genetic approach to study mammalian germline development. K Abe, M S Ko and G R MacGregor

Int. J. Dev. Biol. (1998) 42: 1051-1065

Situs inversus and ciliary abnormalities. What is the connection?

$B$ A Afzelius

Int. J. Dev. Biol. (1995) 39: 839-844

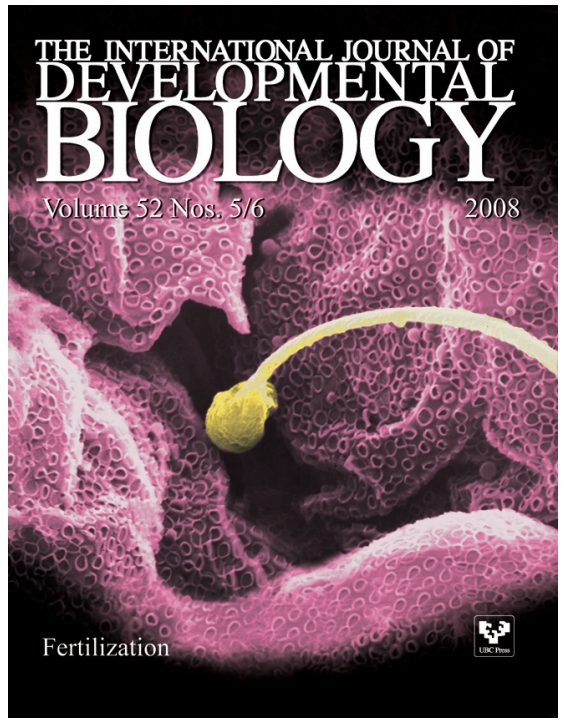

5 yr ISI Impact Factor $(2008)=3.271$

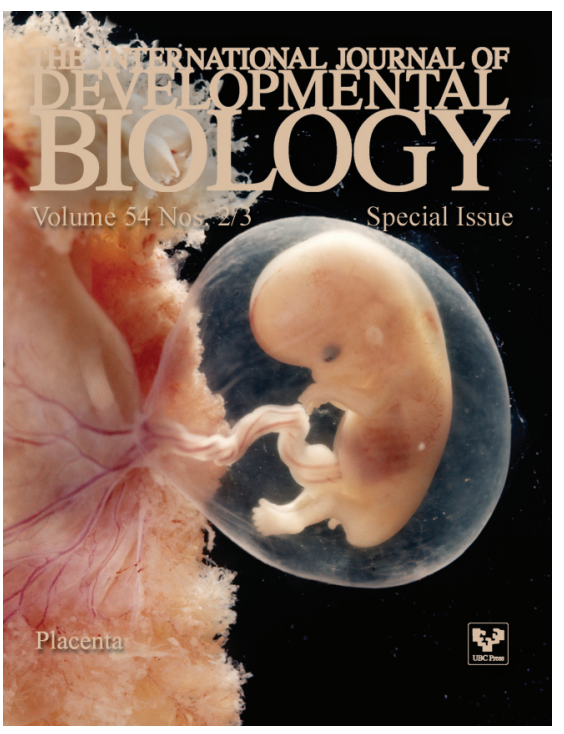

